Professor Whitehead replies as follows:

It is not easy to comment on the letter of Drs $\mathrm{T}$ Cooke and $\mathrm{J}$ Matthews as they do not give a reference to their work. They apparently used a method for a study of adenomatous colonic polyps by harvesting cells by cytological brushing, which is not comparable with our work. They showed that $18 \%$ were aneuploid and expressed "surprise" that we, in our study, did not find aneuploidy in 16 adenomatous polyps. In our discussion it is made quite plain that the conclusion that aneuploidy in polyps does not occur had only a $75-90 \%$ chance of being correct. Furthermore, Drs Cooke and Matthews do not seem to be aware that even frank carcinomas may be diploid. They also assume that the degree of dysplasia in polyps must parallel the degree of cell division activity. This is not necessarily true. The fact that adenomatous polyps and carcinomas may have a profile indicating minimal cell division activity bears this out. The reference to differences in our findings to those of Cuvelier et al is irrelevant.

R WHITEHEAD

Department of Pathology,

Flinders Medical Centre,

The Flinders University of South Australia,

Bedford Park,

South Australia 5042

\section{Eosinophilic gastroenteritis}

I read with interest the review article by Blackshaw and Levison on eosinophilic gastroenteritis, ${ }^{1}$ but I am unhappy about the coverage of parasitic infections, which I think is misleading.

Concerning anisakiasis as a cause of eosinophilic gastroenteritis, the designation of the parasite as "Eustoma rotundatum" was abandoned long ago, ${ }^{2}$ and the invasive larvae belong to the genus Anisakis. Semantics apart, the purported British cases of $1964^{3}$ were not associated with any helminths, and thus there is no evidence to suggest that either of them were, indeed, anisakiasis. The first autochthonous British cases were reported in $1979^{4}$ and $1985 .^{5}$ At the moment, anisakiasis is regarded as the result of actual tissue invasion by larvae rather than the passage through the gastrointestinal tract of the larvae, and therefore a diagnosis of anisakiasis requires the detection of larva or fragments thereof. In the future serodiagnosis may be of help. ${ }^{6}$

I am surprised that giardiasis is mentioned as a cause of prominent gut eosinophilia.
This is not my experience when Giardia lamblia is the sole parasite present, and it is not described in standard texts or in the description of purported invasive giardiasis. $^{7}$

One protozoon that is, however, associated with eosinophilic enteritis is Sarcocystis spp. ${ }^{8}$ This comes from eating meat containing Sarcocystis cysts, whereby man can become the definitive host to the sexual phase in the intestinal mucosa. This may produce an acute enteritis with eosinophilia of the lamina propria. How common the condition is remains uncertain, partly because the parasites are so small they can be readily overlooked.

Hookworm infection may reasonably be diagnosed histologically only if the worms are seen rather than from "erosions or circular channels." Notably, recorded cases of invasive ankylostomiasis are rare. ${ }^{9}$

Other helminths not mentioned in the review are well described as producing eosinophilic gastroenteritis, including oesophagostomiasis and angiostrongyliasis. ${ }^{10}{ }^{11}$ In the United Kingdom invasive enterobiasis happens occasionally, with eosinophilic abscesses in the large bowel wall and serosa (personal observations). More important is the omission of strongyloidiasis as infection with Strongyloides stercoralis may be life threatening. Some cases are diagnosed from intestinal biopsy, where a dense mucosal eosinophilia associated with invasive larvae is seen. ${ }^{10}$

S LUCAS

Department of Histopathology, University College London School of Medicine,

University Street, London WCIE 6JJ

\section{References}

${ }^{1}$ Blackshaw AJ, Levison DA. Eosinophilic infiltrates of the gastrointestinal tract. $J$ Clin Pathol 1986;39:1-7.

${ }^{2}$ van Thiel PH. Anisakiasis. Parasitology 1962; 52:16-7.

${ }^{3}$ Ashby BS, Appleton PJ, Dawson I. Eosinophilic granuloma of gastro-intestinal tract caused by herring parasite Eustoma rotundatum. $\mathrm{Br}$ Med J 1964;i:1141-5.

${ }^{4}$ Watt IA, McLean NR, Girdwood RWA, Kissen LH, Fyfe AHB. Eosinophilic gastroenteritis associated with a larval anisakine nematode. Lancet 1979;ii:893-4.

${ }^{5}$ Lucas SB, Cruse JP, Lewis AAM. Anisakiasis in the United Kingdom. Lancet 1985;ii:843-4.

${ }^{6}$ Kobayashi A, Tsuji M, Wilbur DL. Probable pulmonary anisakiasis accompanying pleural effusion. Am J Trop Med Hyg 1985;34:310-3.

${ }^{7}$ Brandborg LL, Tankersley CB, Gottlieb S, Barancik M, Sartor VE. Histological demonstration of mucosal invasion by Giardia lamblia in
1967:52:143-50.

${ }^{8}$ Bunyaratvej S, Bunyawongwiroj P, Nitiyanant Human intestinal sarcosporidiosis: report of six cases. Am J Trop Med Hyg 1982;31:36-4F

${ }^{9}$ Piza JE, Biagi F. Localisation of Ancylostoma duodenale within the intestinal wall. Pare sitologia 1963;5:189-92.

${ }^{10}$ Marcial-Rojas RA. Pathology of protozoal and helminthic diseases. Baltimore: Williams an Wilkins, 1971.

${ }^{11}$ Morera P. Abdominal angiostrongyliasis: problem of public health. Parasitology Today 1985;1:173-5.

Doctors Levison and Blackshaw reply follows:

We welcome the letter: it reflects Dr Lucas unique experience in the United Kingdom ig parasitology through the London School of Hygiene and Tropical Medicine, and as such, adds considerably to what we said about parasitic infestations. ${ }^{1}$ Our review was written principally for pathologists practising in the "West" and we therefore opted to emphasise and contrast in the fir part of the article "inflammatory fibroid" polyp" and "eosinophilic gastroenteritisర0 and to devote the second part of the artice to other gut lesions with eosinophilia. In the second part of the article we devoted propos tionately more space to lymphomas an histiocytosis $\mathrm{X}$ than some other lesions, åg we have some special experience in the areas, and perhaps our coverage of parasite lesions was consequently sketchier than $\overrightarrow{\vec{B}}$ might have been.

We are grateful to Dr Lucas for his update on the terminology of Anisakis infection for providing references to the "first autoche. thonous British cases," and for referencif? other parasitic causes of eosinophilic enteritis-several of which we freely adm to never having seen personally. As ந் Lucas does rather strongly reprimand ou omission of Strongyloides stercoralis we should like to add to his comment that we have seen several examples of this parasite the bowel without prominent mucosa eosinophilia. We agree that Giardia lamblio is not often associated with prominent gut eosinophilia, but such eosinophilia Ag recorded in what we consider to be a "stanj" dard text". 2 Also, "erosions or circular channels" are considered by the same author to be helpful pointers towards the diagno of hookworm infection. ${ }^{2}$

Apart from these two minor matters of disagreement, we fully accept the pointis made by Dr Lucas and are very pleased wi such a constructive response, broadening, it does, the originally intended scope of the article. 
DA LEVISON

AJ BLACKSHAW

Department of Histopathology,

St Bartholomew's Hospital,

West Smithfield,

London EC1A $7 B E$

\section{References}

${ }^{1}$ Blackshaw AJ, Levison DA. Eosinophilic infiltrates of the gastrointestinal tract. J Clin Pathol 1986;39:1-7.

${ }^{2}$ Whitehead R. Mucosal biopsy of the gastrointestinal tract. 2nd edition. Philadelphia: WB Saunders, 1979:113-5.

\section{New method or new application of a method?}

In a thorough evaluation of a morphometric technique for the assessment of pulmonary arteries Fernie and Lamb claim that the method they use entailing a computer assisted planimeter is new. ${ }^{1}$

The concept of using the internal elastic lamina as a reference for the true size of an artery was pioneered in Britain by Cook and Yates in $1972 .^{2}$ Work, which extended this concept to evaluate the intima and also used computer assisted planimetry, was presented by myself at the summer meeting of the $\mathrm{Pa}$ thological Society of Great Britain and Ireland in Edinburgh in $1983 .^{3}$ A further detailed description of the method was presented at the winter meeting of the society in January $1984^{4}$ and was subsequently published in the Journal of Clinical Pathology..$^{5}$

I would suggest that the paper of Fernie and Lamb represents the application of an established method to a specific problem. While the methodology may be new to the authors working on pulmonary vessels, its advantages and ease of use come as no surprise to those who have already used it to evaluate arteries in other sites.

When the authors presented their work at the Pathological Society summer meeting in 1984 I expressed this point of view and suggested to them that the method was not new. I feel that the world "new" when applied to a method should mean what it says.

J LOWE

Department of Pathology, University Hospital,

Queen's Medical Centre, Nottingham NG7 $2 \mathrm{UH}$

\section{References}

${ }^{1}$ Fernie J, Lamb D. New method for measuring intimal component of pulmonary arteries. $J$
Clin Pathol 1985;38:1374-9.

${ }^{2}$ Cook TA, Yates PO. A critical survey of techniques for arterial mensuration. J Pathol 1972;108:119-27.

${ }^{3}$ Lowe J, Mikulin T. Small vessel disease in arteriosclerosis. J Pathol 1983;141:533.

${ }^{4}$ Lowe J. Morphometric analysis of arterial structure. J Pathol 1984;142:A36.

${ }^{5}$ Lowe J. Method for the morphometric evaluation of arterial structure. J Clin Pathol 1984; 37:1413-5.

Drs Fernie and Lamb reply as follows:

We do not claim any originality with regard to the concept behind our measuring technique, which is the use of the length of the internal elastic lamina as an indicator of artery size. In the first ${ }^{1}$ of our series of papers we refer to the work of Cook and Yates, ${ }^{2}$ who pioneered this technique in Britain, following description of the technique by Furuyama. $^{3}$

On the issue of computer assisted morphometry, such measuring techniques are new to those engaged in studies of the pulmonary vasculature as we pointed out to $\mathrm{Dr}$ Lowe when we presented our work at the summer meeting of the Pathological Society of Great Britain and Ireland in $1984 .{ }^{4}$ Furthermore, we consider that a measuring technique is incomplete if it is not applied to a range of subjects with a view to determining how the data should be analysed and how subjects should be compared. As such an approach has not been adopted in previous studies of the pulmonary vasculature we feel that our paper ${ }^{5}$ makes a new and useful contribution in this area.

Lastly, with regard to Dr Lowe's suggestion that "the paper of Fernie and Lamb represents the application of an established method to a specific problem" we would question whether such methods are truly established. It is interesting that our paper ${ }^{5}$ was rejected by a reputable British pathology Journal in July 1984 on the grounds that there were "queries concerning the fundamental validity of the technique."

JUNE M FERNIE

D LAMB

Department of Pathology, University Medical School,

Teviot Place.

Edinburgh EH8 $9 A G$

\section{References}

${ }^{1}$ Fernie JM, Lamb D. A new method for quantitating the medial component of pulmonary arteries. The measurements. Arch Pathol Lab Med 1985;109:156-62.

${ }^{2}$ Cook TA, Yates PO. A critical survey of techniques for arterial mensuration. J Pathol
1972;108:119-27.

${ }^{3}$ Furuyama M. Histometrical investigations of arteries in reference to arterial hypertension:Tohoku Journal of Experimental Medicines 1962;75:388-414.

${ }^{4}$ Fernie JM, Lamb D. New method for quane titating intimal component of pulmonary arteries. J Pathol 1984;143:303A.

${ }^{5}$ Fernie JM, Lamb D. New method for measuring intimal component of pulmonary arteries. $\rho$ Clin Pathol 1985;38:1374-9.

Fine needle aspiration of thyroid: confusion v. subsequent histology

The review article published in your January 1985 issue $^{1}$ has stimulated us to report somes additional data of fine needle aspiration ob thyroid performed in the department of pathology at Athens University.

During the past few years Greek physi을 cians have increasingly accepted per $-\overrightarrow{-}$ cutaneous, fine needle aspiration in the diagnosis of thyroid nodules. According to many authors, fine needle aspiration is the best procedure currently available for select ing and directing treatment for thyroi\& nodules. ${ }^{2-6}$ In our institution 320 thyroid nodules (1.5-4 cm in diameter) have beers studied by fine needle aspiration since Octo ber 1984. Of these, 12 cases were identified as్ papillary carcinoma, seven as follicular tuํํ mours, two as medullary carcinoma, five a\& unclassified tumours, two as Hurthle cell tu흠 mours, one as lymphoma, and 17 as "sus 3 pected neoplasia." All of the above cases underwent operative treatment by means of the cytology; in addition, 35 patients were clinically selected for surgical biopsy of the nodule despite the fact that the cytologicat diagnosis of fine needle aspiration was nega 2 . tive.

The needling was performed with a 2 은 gauge needle and occasionally with a $2 \widehat{\delta}$ gauge needle. When no adequate materiat had been obtained by the first needling, the procedure was repeated. Double sampling was also performed if the nodule was greater than $2.5 \mathrm{~cm}$ in diameter. The procedure was well accepted by most patients, and nठु appreciable complications or side effect were observed, as in other series. ${ }^{37}$ Miller, however, noted that an intranodular hemas toma can occur, which may be palpated be the physician.

When we examined histologically the $52^{+}$ surgical specimens of biopsied nodules most showed intranodular bleeding. In two of these cases it was so extensive that we coulळ not precisely define the histological patter of the lesion. Moreover, it was impossible to 